Revue de l'Institut des langues et cultures

d'Europe, Amérique, Afrique, Asie et Australie

18 | 2013

Les frontières dans le monde hispanique

\title{
Literatura de avisos e información: por una tipología de una literatura de frontera
}

Notices and Information Literature: For a Typology of Border Literature

\section{Emilio Sola}

\section{OpenEdition}

\section{Journals}

Edición electrónica

URL: http://journals.openedition.org/ilcea/2047

DOI: $10.4000 /$ ilcea.2047

ISSN: 2101-0609

Editor

UGA Éditions/Université Grenoble Alpes

Edición impresa

ISBN: 978-2-84310-251-6

ISSN: $1639-6073$

Referencia electrónica

Emilio Sola, "Literatura de avisos e información: por una tipología de una literatura de frontera », ILCEA [En línea], 18 | 2013, Publicado el 11 julio 2013, consultado el 01 mayo 2019. URL : http:// journals.openedition.org/ilcea/2047 ; DOI : 10.4000/ilcea.2047

Este documento fue generado automáticamente el 1 mayo 2019.

(C) ILCEA 


\section{Literatura de avisos e información: por una tipología de una literatura de frontera ${ }^{1}$}

Notices and Information Literature: For a Typology of Border Literature

\section{Emilio Sola}

«Partiendo de una concepción de la frontera más
cualitativa que la meramente geográfico-político-
jurídica tradicional, se puede entender mejor las
figuras de los viajeros, exiliados o refugiados,
tornadizos o emigrados, administradores y espías,
y sus testimonios literarios de la realidad que
vivieron y lograron narrar; una interesante
literatura de la frontera que desde mi punto de
vista constituye uno de los mayores legados del
Siglo de Oro hispano. En un porcentaje altísimo,
esos textos permanecieron inéditos durante
mucho tiempo, siglos incluso. Tanto en conjunto,
como en fragmentos particulares, de gran altura
expresiva y belleza literaria.»

1 Mi experiencia como historiador, desde mi investigación doctoral sobre España y Japón en el siglo de oro hispano primero ${ }^{2}$, y más tarde como profesor en el Magreb central argelino $^{3}$, me hicieron desarrollar una particular sensibilidad hacia los fenómenos culturales fronterizos, así como la formación de una perspectiva tal que me permite hablar de un hombre de frontera como una categoría o tipología particular; ; más en concreto, de un informador o narrador particular que terminó creando una literatura de la frontera, y que en algunos casos accedió a expresarse en los géneros más clásicos de la creación literaria, como la poesía, el teatro o la novela. Ese fue el caso, por ejemplo, del mismo Cervantes en la literatura hispana del siglo de oro, de Camoes en la literatura portuguesa o de Garcilaso de la Vega el Inca, que desborda la literatura meramente 
cronística, por citar únicamente a tres casos excepcionales del barroco clásico hispano y colonial $^{5}$.

Esos grandes creadores literarios eran solamente la culminación final de un largo proceso de interrelación entre vida y literatura de una multitud de esos hombres de frontera que por razones muy diversas habían tenido que hacer sus vidas en lugares otros de los suyos de origen $y$, de alguna manera, habían conseguido contarlo, informar sobre el otro lado de esas nuevas fronteras vividas, e integrar sus experiencias y conocimientos narrados en la cultura de su nación de origen, en este caso en la cultura barroca hispana y colonial americana del momento, en un primer momento, en la cultura europea en general después.

3 La expansión colonial europea moderna está en la base de esas nuevas fronteras globales que desbordan la concepción cuantitativa y geográfica, político-jurídica o imperial tradicional de demarcación de territorios y fijación de imperios o controles coloniales, y precisa de una aproximación cualitativa más matizada que permita hablar de nuevas fronteras culturales, lingüísticas, religiosas, así como técnicas, económicas o de mentalidades. Dada la estrecha relación existente entre las nuevas fronteras y la información, la transmisión de esa información sobre el otro lado de la frontera sólo podía ser llevada a cabo con éxito por alguno de esos nuevos hombres de frontera, y de ahí una primera tipificación de escritor de vida de acción como creador de una literatura de la frontera, en principio generada para informar o avisar, de ahí lo de literatura de avisos.

4 Escritor y hombre de acción al mismo tiempo, el hecho de que la biografía personal del autor acompañe a lo narrado o expuesto, convierte a ese autor en un hombre excepcional y fuente de información, que puede a su vez ser sujeto o protagonista de una nueva narración, lo cual es también frecuente en la literatura posterior. Su misma vida se convierte en garantía de veracidad de lo que narra o expone, y eso lo diferencia radicalmente del escritor profesional posterior de vida sedentaria, que podrá convertirlo a él en sujeto literario significativo a la vez que fuente de información para sí mismo como autor.

51

Hay un tratado chino sobre literatura de la época Tang que me resultó muy elocuente cuando intentaba tipificar o precisar la esencia de estos textos literarios generados en las fronteras modernas por estos hombres de frontera -viajeros, gobernantes coloniales, misioneros, exiliados o emigrantes- que se titula, en su compleja traducción al español, El corazón de la literatura y el cincelado de dragones. El autor Liu Xie ${ }^{6}$ establece una estrecha relación entre la literatura y el gobierno del estado, y permite hablar de una literatura de la administración, en la que se exigen unas normas determinadas y muy precisas para los textos según se trate de memoriales o cartas diplomáticas, solicitudes, tratados, decretos o leyes, relaciones u otro tipo cualquiera de documento que precise el gobernante para su gobierno. Una compleja tipología de textos literarios pero de gran importancia pues de su buen hacer literario depende la validez misma del documento en cuestión, hasta el punto de que algunos traductores no sabían si la literatura se convertía en la máxima creación del estado o al revés, el estado era la máxima creación de la literatura. Y con ello enlazaba con una de las formulaciones más refinadas de Felipe II en este sentido, recordada por Antonio Domínguez Ortiz, la de que en los negocios de estado las buenas formas es el todo. 
Con estas premisas básicas, me decidí ya abiertamente a considerar literatura, y a veces alta literatura, a la masa documental conservada en los archivos históricos españoles y en la que se narraba, en diferentes fases, las realidades más diversas de los diferentes lugares del imperio hispánico, el mundo mediterráneo, América o el extremo oriente asiático; el descubrimiento mismo de nuevas tierras y mares iban de la mano de los esfuerzos narrativos realizados para relatarlo a la corte hispana y describir aquellos territorios y culturas nuevas con las que se encontraban, o los diferentes episodios que constituían la organización y gobierno de los territorios coloniales, los diferentes conflictos que surgían o los logros de los misioneros católicos, particularmente activos en lo literario los eclesiásticos, además, como señores tradicionales de las letras escritas que eran, por otra parte.

7 Fue precisamente de los medios misioneros jesuitas de Japón de donde procedieron los llamados «Avisos de Japón», por los mismos años que en el Mediterráneo eran omnipresentes en la administración hispana, sobre todo en los medios de la armada naval, los «Avisos de Levante» ${ }^{7}$. Constituían un primer nivel narrativo lleno de viveza y de oralidad, en los mejores casos, de donde procedían ensayos más elaborados que adoptaban una tipología particular, la «relación»"; las «relaciones de avisos» podrían equivaler a un índice o sumario de contenidos que luego podrían ser elaborados en una «Relación» o «Relación verdadera» o similares, un texto ya plenamente literario. De autoría conocida, si el relator de la relación no sabía escribir podía ser ayudado por un escribano profesional: el resultado era una «relación por deposición», en el que el autor o deponente narraba o contestaba un cuestionario sobre el objeto de la relación; a la manera de los procedimientos judiciales, en los que los testigos interrogados terminan permitiendo redactar una verdadera relación de lo sucedido o de lo que se desea informar.

Porque la «relación» está íntimamente ligada a la información, y así está tipificado en un texto de teoría literaria tan atemporal como la de Liu Xie, en el que la relación -esta es la palabra española elegida por la traductora Alicia Relinque Eleta- debe de ser sobria y verdadera para que cumpla su función principal que es informar objetivamente. Es la concepción tradicional de la información al servicio del poder, a quien debe ayudar a solventar las incertidumbres en la toma de decisiones ${ }^{9}$. La necesidad de información es connatural con el imperio, y muy ligada a ello está la lengua, como bien había recordado Nebrija en el prólogo de su gramática de la lengua española; el texto literario escrito va a convertirse en una de las almas de la monarquía, imprescindible para el gobierno de los diferentes territorios imperiales mediterráneos, americanos o asiáticos, fronterizos extremos y por ello protagonistas principales de la literatura de avisos, sujetos principales de la información. Y la relación se convierte en la pieza básica de esa literatura de avisos procedente de las viejas y las nuevas fronteras sobre las que se desea informar.

«Los avisos de cosas que pasan en el mundo», como se los podía llamar también, están en la base, pues, de las relaciones; algunas se elaboraban para darlas a la imprenta, las «relaciones de sucesos», ya en prosa o ya en verso, y alimentaron una industria editorial popular de gran interés que recorre todo el mundo moderno, con frecuencia también ligadas a una propaganda política o ideológica ${ }^{10}$. En los años setenta del siglo XVI también se va estructurando esta información en «Gazetas de avisos» en medios mediterráneos, 
venecianos y florentinos sobre todo, a caballo entre el preperiodismo y los servicios de información ${ }^{11}$. Pero de esta literatura nacida de la necesidad de información de los aparatos de estado - de la monarquía filipina en este caso, pero ya general en toda Europa - destaca la generada por los embajadores y por los espías, más o menos profesionales de la información, y de ellos proceden las piezas literarias más brillantes y de más interés. Más conocidas en el caso de los embajadores, sobre todo por los grandes repertorios documentales editados a partir del siglo XIX ${ }^{12}$, más desconocidas, si no inéditas sin más, las grandes relaciones de los espías, o de aquellos cuya información se juzgó de interés y se conservó manuscrita en los fondos documentales estatales ${ }^{13}$.

104

En mi experiencia investigadora sobre Japón, a través de la documentación principalmente del Archivo General de Indias de Sevilla, las diferentes relaciones de los hispanos por Extremo Oriente, canalizadas hacia España a través de las islas Filipinas y Nueva España o México, constituían un corpus literario estrechamente relacionado con la información y de gran coherencia, podían considerarse literatura de avisos sus piezas principales, y podía hablarse de un grupo de autores tipológicamente hombres de frontera y de gran personalidad, también literaria. Su vida se adaptaba a lo narrado, lo que exponían lo habían visto con sus propios ojos o lo habían oído de testigos presenciales fidedignos, se explicitaban las garantías de veracidad que hacían que la relación pudiera considerarse verdadera. Profesionalmente eran gobernantes (Rodrigo de Vivero), capitanes de barco (Juan Cevicós, Sebastián Vizcaíno), mercaderes exiliados (Bernardino de Ávila Girón), frailes misioneros, más numerosos (Jerónimo de Jesús, Pedro Burguillos, por no citar a los numerosos jesuitas), o algún profesional de la escritura como un escribano de galeón (Alonso Gastón de Cardona) o secretarios o escribanos de los gobiernos coloniales filipinos o mexicanos en general ${ }^{14}$.

115

Mucho más abundantes que esta rica literatura procedente de la frontera extremooriental asiática que puede tipificarse como literatura de avisos o relacionada con la información, es la procedente de los diferentes territorios americanos, de la intensa actividad misionera y de la administración de los diferentes virreinatos y gobernaciones, así como de viajeros privados, en la que no vamos a entrar aquí, dada la mayor difusión de esa literatura colonial renacentista y barroca americana, que va de la más inmediata literatura de avisos o la literatura de la administración y cartas privadas, a los grandes géneros literarios como la poesía, la novela y el teatro, aunque sin alcanzar la genialidad cervantina en el tratamiento de las fronteras mediterráneas. No obstante, obras como las de Bernal Díez del Castillo o Fernández de Oviedo, desbordan la misma obra cronística y conforman obras literarias de alto aliento, en la que se puede descubrir su objetivo principal, el de informar, como un estadio superior de la literatura de avisos ${ }^{15}$.

Mayor complejidad como literatura de frontera, concebida para informar, es la de autores mestizos, como Garcilaso de la Vega o el más complejo aún Huaman Poma de Ayala, aún envuelto en polémicas sobre la naturaleza de su autoría. La misionología americana, además, es muy rica y sus trabajos pueden considerarse variantes de la omnipresente relación, el tipo de documento destinado a informar. Las cortes de Madrid y de Roma se convertían en los centros receptores de esta información, que luego no cesaría de circular poco a poco por toda Europa.

136

En el libro Los que van y vienen, información y fronteras en el Mediterráneo clásico del siglo XVI, 
me fijé especialmente en la transmisión de la información en el Mediterráneo del momento de máximo enfrentamiento habsburgo-otomano, y me topé con la más rica y explícita literatura de avisos procedente de esa gran frontera mediterránea clásica que aún perdura hoy, pues desde entonces no cesó de ensancharse. A mi me gusta llamarle desde entonces la frontera más íntima de Europa, pues la cercanía de los grandes centros de poder del momento, Madrid, Roma y Estambul, del escenario de los conflictos y los enfrentamientos continuos generó una actividad excepcional de los servicios de información que hizo alcanzar su madurez a esa literatura que diéramos en llamar de avisos. Avisos de la Armada, avisos de Levante, avisos de Venecia, avisos de Ragusa, avisos de Argel, constituyen una red informativa que está en la base de las más expresivas relaciones del momento; a lo que se añade que son mucho más abundantes y minuciosas que su correspondiente literatura de avisos americana o filipina.

La tipología de los autores como hombres de frontera es además mucho más variada que la colonial americana o asiática, también hay muchos eclesiásticos católicos, pero hay muchos más viajeros, soldados o mercaderes, cautivos, libertos muladíes o musulmanes nuevos, lo mismo que moriscos o cristianos nuevos, marinos, espías y oficiales regios de todo tipo. Es una frontera próxima, casi íntima, al compararla con las lejanas fronteras coloniales, pero ambas coinciden en hacer llegar esa información a los mismos centros de poder, Madrid y Roma, en este caso, así como Estambul. El Mediterráneo se puede considerar por entonces como el mayor centro de captación de información a nivel mundial, en paralelo a su supremacía económica con la captación masiva de la plata americana también. Suponía, sin duda, el surgimiento de una Europa de la información, previa o en paralelo a la Europa cultural y política. la generada por los procesos judiciales, con su complejidad técnica y su prolijidad, de los que proceden también numerosas relaciones por deposiciones testificales, algunas de ellas novelescas e impregnadas de oralidad, espontáneas y verdaderas. Para su difícil tratamiento literario, que pueda conservar sus valores garantes de veracidad, por ejemplo, habría que experimentar el arte de fragmentar textos complejos, y algunos ensayos hemos llevado a cabo en la plataforma del Archivo de la frontera; en concreto, con las deposiciones testificales procedentes de los diversos procesos hechos a Tommaso Campanella y publicados en el siglo xIx por Luigi Amabile, algunas de esas declaraciones o deposiciones testificales de gran viveza y expresividad literaria ${ }^{16}$.

$16 \quad 7$

Así las cosas, y centrándome en el mundo mediterráneo ya no como centro de captación de información -hemos visto cómo es el Mediterráneo el mayor receptor de información a nivel planetario o global en el siglo de oro- sino como emisor de información, tanto de si mismo, como gran frontera habsburgo-otomana, como emisor también de información sobre las cada vez más lejanas fronteras coloniales; en el caso de la información mediterránea, como primario emisor; en el caso de la información colonial-misionera, como elaborador secundario de la información primaria procedente de las más alejadas fronteras americanas, africanas o asiáticas. En el Mediterráneo, la red de información se convierte en servicios de información cada vez más formalizados, en servicios de Inteligencia.

17 No es raro, por ello, que la mayoría de estos textos informativos procedente de la frontera, esta literatura de avisos, para entendernos, permanecieran inéditos hasta siglos después, o lo sigan aún. Ediciones parciales en repertorios documentales académicos, a 
partir del siglo XIX, cada vez más especializados o contextualizados, no impiden que podamos considerar a esta literatura de avisos primaria como corpus literario inédito. Una tipología literaria, también, a la que le da coherencia su objetivo principal, que es informar, pues le imprime un estilo en el que prima tanto la sobriedad como la minuciosidad, así como la presentación de sus garantías de veracidad, sobre todo en los niveles más primarios, como los avisos de plaza o las relaciones por deposición de un relator o narrador.

Ese es el nivel primario de la literatura de avisos, cuyos protagonistas principales son «los que van y vienen», como se autodenominan en alguna ocasión, los que andan de aquí para allá por esa íntima frontera europea que es el Mediterráneo todo; son básicamente relaciones, más o menos cortas o extensas, notas o sumarios de avisos y relaciones por deposición ante un escribano que recoge lo dicho por un relator. La relación, en fin, ya de avisos de plaza tomados oralmente o cartas de relación escritas por testigos presenciales -que han visto y oído, tal los espías, ojos y orejas del rey- y que constituye la primera garantía de veracidad de la información.

La autoría, en este caso, es más compleja, aunque siempre destaca en ella el protagonista informante, de deriva vital singular que está en la base de su narración de la realidad que interesa conocer. El despliegue de estos autores peculiares es ya singular en si mismo en una mera enumeración: marinos, cautivos, maestros de oficios, escribanos de naves de comercio o de la armada o secretarios virreinales, religiosos y visitadores, espías, correos de avisos, mercaderes, judíos, muladíes o renegados, soldados o auditores, y por encima de todos ellos, embajadores o bailes de los diferentes señores destinatarios de la información.

En ese nivel primario, incluso, se puede hablar de una «narrativa preliteraria ${ }^{17}$, de gran fuerza evocadora en muchas ocasiones. Ya es amplia en los años centrales del siglo XVI, cuando en los años cincuenta la alianza franco-turca llegó a sus resultados más espectaculares, tras la toma de África o Mehedía por los imperiales en Túnez; era un momento delicado tanto para Carlos V, que iba a abdicar muy pronto en su hijo Felipe, como para Solimán, en un momento de enfrentamiento con alguno de sus hijos por razones de transmisión de la herencia imperial, la cuestión sucesoria. Año a año la armada turca salía al Mediterráneo a daño de tierras del rey de España y se coordinaba con la armada francesa con mayor o menor éxito. La literatura de avisos es omnipresente en los archivos de estos momentos, y sus autores peculiares sugieren de inmediato un posible relato interesante. He aquí una somera relación de estos:

- Agustín de la Seta, escribano cautivo de Dragut, autor de una estupenda relación por deposición ante otro escribano, de gran viveza evocadora y narrativa;

- Luis de Mesina y Cesare Fabiano de San Remo, con pintorescas relaciones por deposición, esclavos huidos;

- Domenico Bona y Minico de Nápoles, que estuvieron una semana en la armada turca, o el Griego, último huido de la armada en Proxita, cerca de Nápoles, que conforman otra viva evocación de las galeras turcas en 1552;

- un secretario de Ferrante de Lofredo en Lecce, que en torno a 1553 redactó en español las mejores síntesis y sumarios de avisos, una compleja operación literaria en ocasiones de gran viveza;

- Los virreyes Pedro de Toledo y Juan de Vega, en su abundante correspondencia con la corte española, tienen estupendas cartas de aviso con narraciones sintéticas basadas en la rica literatura de avisos; 
- los embajadores Pedro Hurtado de Mendoza y Francisco de Vargas, tienen también amplio epistolario que sintetiza ese rico caldo de cultivo literario de los avisos, ellos mismos generadores o emisores de «avisos de Venecia»;

- Galaçan de Hesse, caballero alemán cautivo, con una viva relación sobre Berbería de mediados de los cincuenta del xvI, pasada por la mesa de un secretario al español.

Son sólo algunos nombres elegidos por la mayor amplitud de sus textos relacionables con la literatura de avisos o destinada a informar, pero la nómina de posibles autores puede alargarse y alargarse mucho, cada uno de ellos una evocación de una vida de deriva singular, de interés, que tenía qué contar ${ }^{18}$. Algunos de ellos, como Diego Galán, medio siglo después que estos citados, con categoría de alta literatura ${ }^{19}$.

Algunas piezas literarias mayores, tanto por contenido como por extensión, pueden citarse, como la espléndida relación del capitán Baltasar Gago, de 1578, denunciando la mala dirección de una galera de Sicilia capturada en Capri por corsarios berberiscos, en la que viajaba; puede encontrarse una versión en el Archivo de la frontera, procedente el original del archivo de Simancas, en donde se han resaltado los valores de la oralidad, en ocasiones chispeante, del capitán de permiso que ve frustrarse su viaje de regreso a casa y ha perdido también todas sus pertenencias ${ }^{20}$. Por la incompetencia de otros, a los que denuncia. $Y$ con un final sentencioso, en el que elogia esa vida de acción del hombre de frontera: en la acción, «y no en la Corte y entre damas, se muestra el valor y ánimo de cada uno». El título es rotundo: «Verdadera relación de la pérdida de la galera capitana de Palermo, en que venía el ilustrísimo duque de Terranova de Palermo a Nápoles, el mes de abril 1578».

No pocas relaciones, la mayoría inéditas, algunas de gran belleza expresiva como la de Gago, las publiqué en Uchalí, el Calabrés Tiñoso o el mito del corsario muladí en la frontera; al mismo tiempo que trazaba una posible biografía del calabrés que llega a almirante otomano, verdadero arquetipo del hombre de frontera de ascenso social modélico hasta el límite del perfil de «príncipe nuevo» maquiavélico, quise desplegar la riqueza de la documentación con la que se podía reconstruir su biografía. Una documentación plenamente literaria, con toda la variedad tipológica de la literatura de avisos, la literatura de la información o de la frontera. Del aviso de plaza o el aviso de la armada, a los avisos diplomáticos o de espionaje, o a las más amplias relaciones, o libros, con mucha frecuencia inéditos hasta mucho tiempo después; eran autores de aquellos hombres peculiares que tenían qué contar: hombres de frontera que, al mismo tiempo, mantuvieron vivo su amor a la escritura y tuvieron tiempo y modo de poder contar su experiencia, vital e histórica al mismo tiempo, desde la frontera. En el caso de Uchalí, dos contemporáneos suyos, desde la Berbería central argelina, el asturiano Diego Suárez en Orán ${ }^{21}$ y el hasta ahora misterioso Antonio de Sosa en Argel $^{22}$, consiguieron relatos que para la sensibilidad actual pueden considerarse obras maestras de la literatura de avisos, verdadero buque insignia de una posible tipología literaria. Sus biografías mismas respaldan su relato de manera emocionante, relato que nunca podría haberlo escrito alguien sin esa deriva vital de los autores por la frontera mediterránea. El caso de Mármol Carvajal, cautivo en el Magreb muchos años, arabista ${ }^{23}$, Diego de Torres, rescatador de cautivos y cautivo el mismo en Marruecos ${ }^{24}$, al igual que Suárez y Sosa, por citar sólo algunos de obras mayores de alto valor literario, plenas de verismo y expresividad narrativa, en la linde en ocasiones de la narración oral, como en el caso de Diego Galán y su relación del cautiverio de juventud en Estambul, en torno a 1600. Es el caso, también, de Cervantes. 
Cualquiera de las biografías de estos escritores singulares es representativa; ella misma marca toda una tipología posible. El portugués Méndez Pinto puede ser modélico o arquetípico, por no utilizar el término sutil de paradigmático, en el sentido amplio con el que lo utiliza Thomas H. Kung ${ }^{25}$; paradigma de autor de biografía de acción o de frontera, bien pudiera servir como modo de aproximación a una literatura tipificable de manera diferente a la académica actual, literatura del espionaje o literatura de la información.

He aquí la síntesis de su biografía particular, evocación recogida en el Archivo de la frontera:

Fernao Mendes Pinto (Montemor-o-Velho, 1509 -Almada, 1583) es uno de los escritores que forjan la modernidad europea, uno de los de vida más apasionante, de viajero y hombre de acción.

A los 12 años (1522) llega a Lisboa en busca de su primer empleo - como ese viaje literario cervantino de Rinconete y Cortadillo-, y tras año y medio de «servir a un amo» - una ama en este caso, una señora noble-, decidió huir y embarcarse en una carabela que terminará asaltada por piratas y frustró su primer viaje de huida, podría decirse. Un viaje en busca de Fortuna -aunque en este caso fuera mal afortunado- para evitar «servir a un amo», tal la formulación de Cortadillo al final del relato cervantino en Sevilla, cuando quiere al menos retardar la llegada de un destino vital.

En 1537, con 28 años, consigue por fin embarcarse para la India, después de pasar unos años de criado en el entorno de caballeros santiaguistas. Y ahí comienza su "peregrinación», como se denominaba a los viajes fuera de la "patria». El «peregrino» pasa a ser el arquetipo literario - y vital sin duda- de ese hombre moderno que ha emergido en ese primer atisbo de mundo global que apunta en el siglo XVI europeo.

No regresó a Lisboa hasta 1558, y al año siguiente se casó con María Correia de Brito, ya con 50 años, con quien tuvo dos hijas. Su «peregrinación» de más de 20 años comenzó a narrarla a los 60 años, ya anciano para entonces, cuando se consideraban los 62 años edad «normalmente de gran peligro» para un hombre. En 1580 concluía la narración en su casa de Almada, en el Pragal (Portugal), y tres años después moría, a los 6 meses de que Felipe II, nuevo rey de Portugal, le concediera la gracia de una renta anual en reconocimiento de sus servicios a la Corona.

Sus viajes por la India, desde Díu, y con un episodio de esclavitud en Moca y Ormuz, con un amo griego y otro hebreo (1537-1538), los narra en los primeros capítulos de su libro. Luego siguen viajes entre Díu, Goa y Malaca, con dos viajes a Sumatra (1539), viajes por la costa de China y a Japón por primera vez (1542), a Pekín y otros lugares de China (1543-1544), una segunda estancia de casi seis meses en Japón (1546), otros viajes por el Sudeste asiático, una tercera estancia en Japón, donde se encuentra con Francisco Javier en Bungo (1551), cuya muerte al año siguiente en una isla cerca de Cantón narra en el capítulo 215 de su libro, una navegación de Siam a Goa (1553), y nuevos viajes a Japón entre 1554 y 1556, durante dos años novicio jesuita. Finalmente, deja voluntariamente la Compañía de Jesús y vuelve a Goa, capital colonial portuguesa, y de allí a Lisboa en 1559, para iniciar su etapa de padre de familia y escritor. Todo un clásico ${ }^{26}$.

$26 \quad 10$

Volvamos al Mediterráneo de Uchalí. Una de las relaciones más sugestivas de las publicadas en el ensayo de biografía de Uchalí citado ${ }^{27}$, es la «Relación dada por mí, Jaime de Losada, del viaje que hice a Constantinopla por orden del señor duque de Terranova, fecha en Otranto a los 15 de diciembre 1575». Un informe espléndido a medio camino entre el de un embajador y un espía, y que termina unos días antes de su muerte, en Otranto, de regreso de Estambul. Losada era un marino, capitán de galera en Lepanto, que 
había sido en una etapa de su vida cautivo en la casa del calabrés Uchalí, con el que mantenía una buena amistad y relación. Había sido también, más de una vez, en este su último viaje mismo, portador de las ofertas de ennoblecimiento que Felipe II hacía a su antiguo súbdito calabrés si dejaba el servicio del Gran Turco y pasaba a su servicio, como señor natural suyo que era. Toda la maestría evocadora de Jaime Losada glosa muy bien las complejas relaciones tejidas en la cotidianeidad de la frontera como lugar de intercambios constantes, negocios políticos o económicos, información o estructuras administrativas o financieras. Su despedida en la relación es todo un emblema (negociar, ver, colegir): «Esto es en substancia lo que he negociado, visto y colegido en este viaje...» Y eso es lo que envía a su excelencia, a su señor, destinatario de la información.

Los servicios de información más formalizados tienen en el Mediterráneo máxima actividad, y en el decenio de los años setenta del siglo xVI crean series de relaciones y de avisos de gran viveza y expresividad: nombres como Aurelio Santa Croce, Joan Agostino Gilli o Renzo de San Remo, en italiano o con versiones en español de algunos de sus textos principales, agentes de la llamada "conjura de los renegados»" ${ }^{28}$ o españoles como Antón Avellán y Antonio de Chávarri o Echavarri, son autores refinados de esta posible tipología de la literatura de avisos. Todos con una biografía de acción novelesca en la frontera, garantía primera de la autenticidad de sus relaciones, de su información.

Se puede decir que esta literatura de avisos primaria está en la base de la gran literatura de la información que sería la correspondencia diplomática, tan rica y generalizada ya en el siglo XVI. Las cartas y relaciones de los embajadores venecianos, de las que he manejado en particular las de los bailos de Estambul ${ }^{29}$, o las de las embajadas y encargados de negocios franceses publicadas por Charrière, constituyen un estadio superior de esta literatura de la información, y con frecuencia basan o fundamentan sus exposiciones y análisis en esta literatura de avisos más primaria. Autores como Diego Hurtado de Mendoza o François de Noailles, obispo d'Aix, o Lorenzo Bernardo o Francesco Moresini, o el Busbequio, deberían de figurar en las historias de una literatura europea normalizada sin duda alguna. Lo mismo que esos autores mayores destacados ya citados, Mármol, Sosa, Torres, Suárez, Galán o el mismo Cervantes. Una literatura que está en la base de una Europa de la información de la que procedemos todos.

\section{BIBLIOGRAFÍA}

ALONSO ACERO Beatriz, Sultanes de Berbería en tierras de la Cristiandad: exilio musulmán, conversión y asimilación en la Monarquía Hispánica (siglos XVI-XVII), Barcelona, Bellaterra, 2005.

ALZAMORA Juan Luis, La vida, y historia de Hayradín, llamado Barbarroja, edic. de M. Á. Bunes y E. Sola, Granada, Universidad de Granada, 1997.

BENNASAR Bartolomé y Lucille, Los cristianos de Alá. La fascinante aventura de los renegados, Madrid, Nerea, 1989.

BELHAMISSI Moulay, Les captifs algériens et l'Europe chrétienne, Argel, Enal, 1988. 
BocCADAMo Giuliana, La redenzione dei cattivi, Nápoles, M. D’Auria Ed., 1985.

BONAFINI Gioseppe, La Sicilia e il mercato degli schiavi alla fine del Cinquecento, Palermo, Ila Palma, 1983.

BONO Salvatore, Corsari nel Mediterraneo. Cristiani e musulmani fra guerra, schiavitù e comercio, Milano, Mondadori, 1993.

—, Schiavi musulmani nell'Italia moderna. Galeotti, vu'cumprà, domestici, Nápoles, Ed. Scientifiche Italiane, 1999.

BUNES IBARRA Miguel Ángel de, La imagen de los musulmanes y del Norte de Africa en la España de los siglos XVI y XVII. Los caracteres de una hostilidad, Madrid, C.S.I.C., 1989.

—, Los Barbarroja. Corsarios del Mediterráneo, Madrid, Aldebarán, 2004.

CAMAMIS George, Estudios sobre el cautiverio en el Siglo de Oro, Madrid, Gredos, 1977.

CONTRERAS Alonso de, «Discurso de mi vida», in José María de Cossio (ed.), Autobiografías de soldados (s. XVII), Madrid, Atlas, 1956.

DELUMEAU Jean, Rome au XVI e siècle, París, Hachette, 1975.

ECO Umberto, Interpretación y sobreinterpretación, Cambridge, Cambridge Univ. Press, 1992.

ÉTIENVRE Jean-Paul, «Entre relación y carta: los avisos», in Las Relaciones de Sucesos en España (1500-1750). Actas del I encuentro de Relaciones de Sucesos, Alcalá, Univ. de la Sorbona / Univ. de Alcalá, 1996.

FLORISTÁN José Manuel, Fuentes para la política oriental de los Austrias. La documentación griega del Archivo de Simancas (1571-1621), León, Universidad, 2 vols., 1988.

GALÁN Diego, Cautiverio y trabajos, Manuel Serrano y Sanz (ed.), Madrid, Sociedad de Bibliófilos Españoles, 1913.

-, Relación del cautiverio y libertad de Diego Galán, Miguel Ángel de Bunes y Matías Barchino (eds.), Toledo, Diputación provincial de Toledo, 2001a.

-, Edición crítica de Cautiverio y Trabajos de Diego Galán, Matías Barchino (ed.), Cuenca, Univ. de Castilla-La Mancha, 2001b.

GRACIÁN DE LA MADRE DE DIOS Gerónimo, Tractado de la redempción de captivos, en que se cuenta las grandes miserias que padescen los christianos que están en poder de infieles, y de la qual sancta obra sea de su rescate, $y$ de algunos medios y appuntamitos para ello, Roma, Giacomo Luna, 1597; 1942: fragmentos a cura di Luis Rosales, Madrid, Fé.

HAEDO Diego de, Topographia e historia general de Argel, Ignacio Bauer y Landauer (ed.), Madrid, Sociedad de Bibliófilos españoles, 3 vols., 1927.

HEERS Jacques, Les barbaresques : La course et la guerre en Mediterranée, XIV ${ }^{e}-X V I^{e}$ siècles, París, Perrin, 2001.

HERNANDO SÁNCHEZ Carlos José, Castilla y Nápoles en el siglo XVI. El virrey Pedro de Toledo, Salamanca, Junta de Castilla y León, 1994.

HESS Andrew C., The forgotten frontier. A history of the Sixteenth Century Ibero-African frontier, Chicago-Londres, Univ. Chicago Press, 1978.

IBÁÑ̃ZZ Jesús, A contracorriente, Madrid, Fundamentos, 1997. 
Iovino María Pía, «L'incubo turco», in Imma Ascione (ed.), Napoli e Filippo II, Nápoles, Gaetano Marcchiaroli Ed., 1998, pp. 64-67.

LENCI Mario, Lucca, il mare e i corsari barbareschi nel XVI secolo, Lucca, Maria Pacini Fazzi Ed., 1987. LÓPEZ DE GÓMARA Francisco, Guerras del mar del Emperador Carlos V, Miguel Ángel Bunes y N. E. Jiménez (eds.), Madrid, Sociedad Estatal para la Celebración de los Centenarios de Felipe II y Carlos V, 2000.

MAFRICI Mirella, Mezzogiorno e pirateria nell'età moderna (secoli XVI-XVIII), Nápoles, Ed. Scientifiche Italiane, 1995.

MANCA Ciro, Il modelo di sviluppo economico della città marittime barbaresche dopo Lepanto, Nápoles, Giannini Ed., 1982.

MARIÑo Primitivo, Tratados internacionales de España, Carlos V. España y el norte de Africa, Madrid, CSIC, 1980.

MÁRMOl CARVAJAL Luis, Descripción general de Africa, facsímil I tomo, Madrid, CSIC, 1953.

MARTÍNEZ TORRes José Antonio, Prisioneros de los infieles. Vida y rescate de los cautivos cristianos en el Mediterráneo musulmán (siglos XVI-XVII), Barcelona, Bellaterra, 2004.

MAS Albert, Les Turcs dans la littérature espagnole du Siècle d'or, París, Centre de recherches hispaniques, 1967.

MIGNOLO Walter, «Experiencia y verdad en la crónica de Indias», in Francisco Rico (ed.), Historia y crítica de la literatura española, Barcelona, Crítica, 1991.

мотTA Giovanna (ed.), I turchi, il Mediterraneo e l'Europa, Milano, Franco Angeli, 1998.

oCHOA BRUN Miguel Ángel, Historia de la diplomacia española. La diplomacia de Carlos V, Madrid, Ministerio de Asuntos Exteriores, 1999.

OLIVER ASÍN Jaime, «La hija de Agi Morato», in Boletín de la Real Academia Española, XXVII, 1948, pp. 244-389.

-, Vida de don Felipe de África, príncipe de Fez y Marruecos (1566-1621), Madrid-Granada, CSIC, 1955. PARDO MOLERO Juan Francisco, La defensa del imperio. Carlos V, Valencia y el Mediterráneo, Madrid, Sociedad Estatal para la Celebración de los Centenarios de Felipe II y Carlos V, 2001.

Renegados, viajeros y tránsfugas. Comportamientos heterodoxos y de frontera en el siglo XVI, Alcalá, Fugaz, 2000.

RODRÍGUEZ SALGADo María José, Un imperio en transición. Carlos V, Felipe II y su mundo, Barcelona, Crítica, 1992

SASTRE PORTELLA Fernando, «Joan Seguì Alzina, un ciutadellenc a la Cort del Gran Turc», in Publicacionjs des Born, 6, Ciutadella de Menorca, Cercle Artistic, 1998, pp. 115-135.

SCARAFFIA Lucetta, Rinnegati. Per una storia dell'identità occidentale, Bari, Laterza, 1993.

SCARAMELLA Pierroberto, Con la croce al core. Inquisizione ed eresia in Terra de Lavoro (1551-1564), Nápoles, La Città del Sole, 1995.

Sola Emilio, Libro de maravillas del oriente lejano, Madrid, Editora Nacional, 1980.

-, Argelia, entre el desierto y el mar, Madrid, Mapfre, 1993.

-, Historia de un desencuentro. España y Japón, 1580-1614, Alcalá, Fugaz, 1999. 
-, «Barbarroja, Dragut y Alí Bajá, señores de la frontera mediterránea», in Ana Sánchez Fernández (ed.), II Congreso internacional de estudios históricos. El Mediterráneo: un mar de piratas y corsarios, Alicante, Ayuntamiento de Santa Pola, 2002.

-, Los que van y vienen. Información y fronteras en el Mediterráneo clásico del siglo XVI, Alcalá, Universidad, 2005.

-, La Conjura de Campanela, Madrid, Turpín Ed., 2007.

-, Uchalí, el Calabrés Tiñoso o el mito del corsario muladí en la frontera, Barcelona, Bellaterra, 2010.

SOLA Emilio y DE LA PEÑA José Francisco, Cervantes y la Berbería. Cervantes, mundo turco-berberisco y servicios secretos en la época de Felipe II, Madrid, Fondo de Cultura Económica, 1995.

sosA Antonio de, Diálogos de los mártires de Argel, Emilio Sola y José María Parreño (eds.), Madrid, Hiperión, 1990.

-, An Early Modern Dialogue with Islam. Antonio de Sosa's Topography of Algiers, María Antonia Garcés y Diana de Armas Wilson (eds.), Notre Dame, Indiana, Universidad de Notre Dame, 2011.

SUÁREZ Diego, Historia del maestre último que fue de Montesa y de su hermano don Felipe de Borja. La manera como gobernaron las plazas de Orán y Mazalquivir, reinos de Tremecén y Ténez..., Miguel Ángel de Bunes Ibarra y Beatriz Alonso Acero (eds.), Valencia, Instituciò Alfons el Magnànim, 2004.

TENENTI Alberto, «I corsari in Mediterraneo all'inizio del cinquecento», in Rivista Storica Italiana, LXXII, 1960, pp. 230-286.

TORRES Diego, Relación del origen y suceso de los Xarifes..., Mercedes García-Arenal (ed.), Madrid, Siglo XXI, 1980.

Viaje de Turquía, García Salinero (ed.), Madrid, Cátedra, 1986.

XIE Liu, El corazón de la literatura y el cincelado de dragones, edic. de Alicia Relinque Eleta, Granada, Comares, 1995.

\section{NOTAS}

1. Este trabajo es un ensayo reflexivo y una invitación a otros investigadores a valorar desde el punto de vista literario la abundante documentación archivística que recojo y comento en mis libros citados a lo largo de él, y a la que intento tipificar como literatura de avisos o literatura de la frontera.

2. Ver E. Sola, Historia de un desencuentro. España y Japón, 1580-1614, Alcalá, Fugaz, 1999.

3. Ver E. Sola, Argelia, entre el desierto y el mar, Madrid, Mapfre, 1993.

4. Ver E. Sola y J. F. De La Peña, Cervantes y la Berbería. Cervantes, mundo turco-berberisco y servicios secretos en la época de Felipe II, Madrid, Fondo de Cultura Económica, 1995 y E. Sola, Los que van y vienen. Información y fronteras en el Mediterráneo clásico del siglo XVI, Alcalá, Universidad, 2005.

5. Interesante W. Mignolo, «Experiencia y verdad en la crónica de Indias», en F. Rico (ed.), Historia y crítica de la literatura española. 2/1: Siglos de oro: Renacimiento, Barcelona, Crítica, 1991, pp. 128-130. 6. Ver L. Xie, El corazón de la literatura y el cincelado de dragones, edic. de Alicia Relinque Eleta, Granada, Comares, 1995.

7. Ver una posible tipología de este tipo de autores en el ya citado E. Sola (Los que van y vienen. Información y fronteras en el Mediterráneo clásico del siglo XVI, op. cit., pp. 15-26). 
8. Ver J.-P. Étienvre, «Entre relación y carta: los avisos», in Las Relaciones de Sucesos en España (1500-1750). Actas del I encuentro de Relaciones de Sucesos, Alcalá, Univ. de la Sorbona / Univ. de Alcalá, 1996.

9. Ver J. Ibáñez, A contracorriente, Madrid, Fundamentos, 1997, pp. 423 ss.

10. Desde 1996 se celebran encuentros internacionales de la Sociedad Internacional para el estudio de las Relaciones de Sucesos (SIERS), cuyas actas son de gran interés para este asunto, comenzando por el primer encuentro Las Relaciones de Sucesos en España (1500-1750), Alcalá, Universidad de Alcalá / Universidad de la Sorbonne. Particular interés tiene el tercer encuentro, Encuentro de Civilizaciones (1500-1750). Informar, narrar, celebrar, Alcalá, Universidad de Alcalá / Universidad de Cagliari, 2003.

11. Las primeras gazetas de avisos así rotuladas aparecen en el Archivio di Stato de Florencia, en la correspondencia de sus agentes en Venecia en los años setenta del siglo XVI, en particular los envíos de información de Ottavio Abbioso y Orazio Urbani.

12. De particular interés, para España, pero muy desordenada la documentación, es la Colección de Documentos Inéditos para la Historia de España (CODOIN), en 113 volúmenes editados desde mediados del siglo XIX. En las series similares francesas, particular interés para Oriente tiene la colección editada en 4 vols. por E. Charrière, Négociations de la France dans le Levant, París, 1840-1860.

13. Muchas de estas relaciones procedentes de la actividad informativa de los espías las utilicé en mi reciente biografía de Alí Bajá, el Uchalí cervantino, ver E. Sola (Uchalí, el Calabrés Tiñoso o el mito del corsario muladí en la frontera, Barcelona, Bellaterra, 2010).

14. En el Archivo de la frontera, <www.archivodelafrontera.com>, hemos recogido alguna de estas piezas más señaladas, prácticamente inéditas hasta finales del siglo XIX o hasta el siglo XX, aunque habían sido utilizadas por historiadores y misionólogos con anterioridad. Así, la relación de Burguillos o las de Vivero y Cevicós, polemizando entre sí sobre la conveniencia o no de abrir amplias relaciones desde Filipinas y Nueva España con Japón. Ver también, para el caso de Japón, E. Sola (Libro de maravillas del oriente lejano, Madrid, Editora Nacional, 1980 y Historia de un desencuentro. España y Japón, 1580-1614, Alcalá, Fugaz, 1998).

15. Puede verse una interesante selección de estudios sobre esta literatura americana en la citada Historia y crítica de la literatura española, coordinada por Francisco Rico, vol. 2, cap. 4 «Historias y Experiencias», por autores tan estimulantes como Pérez de Tudela, Hanke, Gilman, Avalle-Arce o Caro Baroja, pp. 225-270.

16. Ver E. Sola (La Conjura de Campanela, Madrid, Turpín Ed., 2007), que es un relato elaborado con estos materiales judiciales, que a su vez estamos publicando en la plataforma del Archivo de la frontera, traducidos los interrogatorios del italiano, siguiendo la edición de Luigi Amabile del siglo XIx. Puede verse en <www.archivodelafrontera.com/e-libros/la-conjura-de-campanella-2/>.

17. E. Sola, Los que van y vienen. Información y fronteras en el Mediterráneo clásico del siglo XVI, op. cit., p. 39.

18. Muchas de estas piezas literarias las edito en E. Sola (Uchalí, el Calabrés Tiñoso o el mito del corsario muladí en la frontera, op. cit.), así como en <www.archivodelafrontera.com>.

19. Ver D. Galán, Relación del cautiverio y libertad de Diego Galán, M. Á. de Bunes Ibarra y M. Barchino (eds.), Toledo, Diputación provincial de Toledo, 2001a y Edición crítica de Cautiverio y Trabajos de Diego Galán, Matías Barchino (ed.), Cuenca, Univ. de Castilla-La Mancha, 2001b.

20. Ver edición digital: <www.archivodelafrontera.com/clasicos-minimos/una-batalla-naval-encapri-narrada-por-el-capitan-baltasar-gago/>.

21. Ver D. Suárez, Historia del maestre último que fue de Montesa y de su hermano don Felipe de Borja. La manera como gobernaron las plazas de Orán y Mazalquivir, reinos de Tremecén y Ténez..., M. Á. de Bunes Ibarra y B. Alonso Acero (eds.), Valencia, Instituciò Alfons el Magnànim, 2004. 
22. Ver A. de Sosa, Diálogos de los mártires de Argel, E. Sola y J. M. Parreño (eds.), Madrid, Hiperión, 1990 y An Early Modern Dialogue with Islam. Antonio de Sosa's Topography of Algiers, M. Antonia Garcés y D. de Armas Wilson (eds.), Notre Dame, Indiana, Universidad de Notre Dame, 2011.

23. Ver edición facsímil, L. Mármol Carvajal (Descripción general de Africa, Madrid, CSIC, 1953), del primero tomo de la edición del XVI.

24. Ver D. Torres, Relación del origen y suceso de los Xarifes..., M. García-Arenal (ed.), Madrid, Siglo XXI, 1980.

25. T. S. Kung, La estructura de las revoluciones científicas, Madrid, Orbis, 1982 (8. a reimpr.), p. 44.

26. Ver < www.archivodelafrontera.com/bibliografia/la-peregrinacion-de-fernao-mendes-pintoluisa-trias-folch-madrid-2003-editorial-sintesis-207pp/>.

27. E. Sola, Uchalí, el Calabrés Tiñoso o el mito del corsario muladí en la frontera, op. cit., pp. 220-231.

28. E. Sola, Los que van y vienen. Información y fronteras en el Mediterráneo clásico del siglo XVI, op. cit., cap. IV «La conjura de los renegados», pp. 199-246.

29. En el Archivo de Estado de Venecia, en la sección Dispacci Ambasciatoi, Constantinopoli, se conserva toda esa rica correspondencia desde los años sesenta del siglo XVI.

\section{RESÚMENES}

Partiendo de una concepción de la frontera más cualitativa que la meramente geográficopolítico-jurídica tradicional, se puede entender mejor las figuras de los viajeros, exiliados o refugiados, tornadizos o emigrados, administradores y espías, y sus testimonios literarios de la realidad que vivieron y lograron narrar; una interesante literatura de la frontera que desde mi punto de vista constituye uno de los mayores legados del Siglo de Oro hispano. En un porcentaje altísimo, esos textos permanecieron inéditos durante mucho tiempo, siglos incluso. Tanto en conjunto, como en fragmentos particulares, de gran altura expresiva y belleza literaria.

If we start understanding the border in a way more qualitative than the traditional: a border merely geographical, political, and legal, it can be better understood the characters of the travelers, exiles and refugees, tornadizos or emigrants, administrators and spies, and their literary evidences of the reality they lived and managed narrate; and from my point of view an interesting literature of the border which is one of the greatest legacies of the Spanish Golden Age. In a very high percentage, these texts remained unpublished for a long time, even centuries. Texts-even considered both overall as in particular fragments-of a high rise expressive and literary beauty.

\section{ÍNDICE}

Palabras claves: descubrimientos geográficos, mundo colonial, frontera, diplomacia, espionaje, información, literatura de avisos, viajeros, relación

Keywords: notices, information, border, literature, espionage 
AUTOR

EMILIO SOLA

Université d'Alcala de Henares (Espagne) 